\title{
PELATIHAN DAN PEMBENAHAN MANAJEMEN BISNIS DAN PEMBUKUAN KUPIAH TRADISIONAL PADA PENGRAJIN “LILI KOLEKSI” KECAMATAN LUBUK KILANGAN KOTA PADANG
}

\author{
Ermatati Hatta' ${ }^{1}$ Dita Maretha Rissi ${ }^{2}$, Welsi Haslina ${ }^{3}$, Gustati ${ }^{4}$ \\ ${ }^{1}$ Jurusan Akuntansi Politeknik Negeri Padang \\ Email: ermatati.hatta@gmail.com \\ ${ }^{2} J u r u s a n$ Akuntansi Politeknik Negeri Padang \\ Email: ditamaretharissi@gmail.com \\ 3Jurusan Akuntansi Politeknik Negeri Padang \\ welsih@yahoo.com \\ ${ }^{4}$ Jurusan Akuntansi Politeknik Negeri Padang \\ Email: gustati1602@yahoo.com
}

\begin{abstract}
Lili Collection is one of the traditional skullcap craftsmen who are on Jl. Beringin RT 01 / RW 01, Lubuk Kilangan Subdistrict, Padang City since 2009. With the speed of development in the industrial world, this business is experiencing difficulties in developing its business and losing market share. This handicraft business has not carried out financial bookkeeping in accordance with UMKM standards. The purpose of this activity is to help traditional skullcap craftsmen to develop their businesses through training and business management and bookkeeping improvements tailored to this type of business, namely MSMEs. So that the hope of this activity is that it can help partners develop their businesses and gain market share in the eyes of the community through proper business management. What is no less important is the existence of this activity, it is hoped that partners will be able to do financial bookkeeping properly according to the MSME standards. This bookkeeping is useful for partners to know their financial position and make this financial information the basis for future decision making.
\end{abstract}

Keywords: management business, bookepping

\begin{abstract}
Abstrak
Lili Koleksi merupakan salah satu pengrajin kopiah tradisional yang berada di Jl. Beringin RT 01/ RW 01 Kecamatan Lubuk Kilangan Kota Padang sejak tahun 2009. Dengan kecepatan perkembangan di dunia indrustri, usaha ini mengalami kesulitan dalam mengembangkan usahanya dan kehilangan pangsa pasar. Usaha kerajinan ini belum melakukan pembukuan keuangan sesuai dengan standar UMKM. Tujuan dari kegiatan ini adalah membantu usaha pengrajin kopiah tradisional untuk mengembangkan usahanya melalui pelatihan dan pembenahan manajemen bisnis dan pembukuan yang disesuaikan dengan jenis usaha ini yaitu UMKM. Sehingga harapan dari kegiatan ini adalah dapat membantu mitra mengembangkan usahanya dan mendapatkan pangsa pasar di mata masyarakat melalui manajemen bisnis yang tepat. Yang tidak kalah pentingnya lagi dengan adanya kegiatan ini, diharapankan mitra dapat melakukan pembukuan keuangan dengan baik sesuai dengan standar UMKM. Pembukuan ini bermanfaat bagi mitra untuk mengetahui posisi keuangannya dan menjadikan informasi keuangan tersebut sebagai dasar dalam pengambilan keputusan dimasa yang akan datang.
\end{abstract}

Kata Kunci: Manajemen bisnis, pembukuan 


\section{Pendahuluan}

UMKM merupakan bagian dari industri kreatif, yang merupakan suatu kegiatan usaha yang focus pada kreasi dan inovasi. Indonesia merupakan Negara yang kaya akan budaya serta tradisi yang bisa menjadi sumber kreativitas. Kontribusi ekonomi kreatif terhadap produk domestic bruto (PDB) Indonesia pada tahun 2015 adalah 748,82 triliun dan tahun 2016 menjadi Rp 852 triliun atau meningkat 8.6\%. Dari total kontribusi tersebut sub sector kuliner, kriya, dan fashion memberikan kontribusi terbesar pada ekonomi kreatif. Sub sector kuliner tercatat berkontribusi sebesar 41.69\%, kemudian fashion sebesar $18.15 \%$ dan kriya sebesar 15.70\%. Selain itu, industry film bertumbuh $10.28 \%$, musik 7.26\% , seni/arsitektur 6.62\% dan games tumbuh 6.68\% (Kompas.id:2019).

Berdasarkan data tersebut seharusnya UMKM mendapat perhatian yang serius dari pemerintah dan pihak lainnya agar dapat dibina dan dikembangkan sehingga UMKM mampu menjadi penopang perekonomian Indonesia dan sekaligus memberdayakan masyarakat secara mandiri. Selama ini kenyataannya UMKM masih menghadapi berbagai permasalahan diantaranya adalah lemahnya permodalan dan sulit mengakses sumber modal perbankan, kurangnya pasokan bahan baku, terbatasnya pemasaran produk, akses informasi, dan masalah lingkungan. Akibatnya UMKM sulit berkembang dan tidak mampu bersaing. Oleh karena itu sangat diperlukan melakukan pembinaan dan pengembangan terhadap UMKM.

Permasalahan-permasalahan diatas merupakan faktor yang menghambat kemajuan UMKM yang berdampak kepada pertumbuhan dan daya saing UMKM. Terlebih lagi dengan pemberlakuan pasar bebas ASEAN tidak menutup kemungkinan akan banyak produkproduk dari UMKM asing yang masuk ke Indonesia. Kondisi ini menjadi tantangan bagi produk UMKM Indonesia sehingga sangat diperlukan pembinaan, pemberdayaan, pembenahan dan pendampingan.

Provinsi Sumatera Barat khususnya di Kota Padang, mempunyai sentra UMKM yang tersebar dibeberapa tempat. Tidak sedikit pula yang berprofesi sebagai pengusaha khususnya pelaku usaha UMKM seperti pelaku usaha makanan, usaha bengkel, ataupun usaha kerajinan seperti pembuatan kopiah tradisional dan lainnya. Masih banyak terdapat pelaku usaha UMKM yang masih bersifat merintis kegiatan usahanya namun ada pula pelaku usaha yang telah lama melakukan kegiatan usahanya namun masih belum berkembang dengan baik. Berdasarkan survey yang telah dilakukan oleh tim penulis menunjukan bahwa, tingginya kegiatan bisnis yang dilakukan oleh pelaku usaha namun belum disertai dengan pemahaman manajemen bisnis dan minimnya kesadaran melakukan pembukuan dalam melakukan kegiatan bisnis. Pelaku usaha hanya fokus pada profit semata tanpa memperhatikan faktor-faktor pendukung usaha seperti faktor manajemen bisnis dan pembukuan.

Berdasarkan ilustrasi tersebut, pelaku usaha UMKM membutuhkan pemahaman mengenai manajemen bisnis dan pembukuan usaha untuk mendukung kegiatan usaha agar dapat berkembang dengan baik dimasa yang akan datang. Salah satunya UMKM yang berada di wilayah Kecamatan Lubuk Kilangan adalah kerajinan kopiah tradisional Lili Koleksi. Sentra UMKM kerajian kopiah tradisional ini berada di Jl. Beringin RT 01/ RW 01 Kecamatan Lubuk Kilangan Kota Padang. UMKM ini merupakan usaha rumahan dengan tenaga kerja yang berjumlah kurang lebih empat orang yang sudah berdiri sejak tahun 2009. Manajemen usaha kerajinan kopiah tradisional masih sederhana dan belum 
menerapkan strategi manajemen bisnis yang baik. Selain itu usaha ini belum melakukan pembukuan terkait keuangan usahanya. UMKM kerajinan kopiah tradisional yang menjadi pengamatan tim penulis adalah usaha kerajinan milik ibu Candra Wita.

Dari pengamatan dan analisis situasi, permasalahan yang dihadapi oleh pemilik usaha adalah belum menggunakan manajemen bisnis seperti belum ada pemisahan fungsi karyawan, belum ada media promosi untuk memperkenalkan produknya dan hanya menunggu pelanggan yang datang, tidak mampu bersaing karena tidak melakukan inovasi produk, tidak memiliki perencanaan kedepan dan tidak ada kontrol terkait keuangan karena tidak melakukan pembukuan. Dengan tidak diterapkannya manajemen bisnis dan pembukuan yang baik membuat usaha ini semakin sulit berkembang dan berinovasi. Walaupun terdapat tingginya keinginan berbisnis namun tidak disertai dengan pemahaman strategi manajemen yang baik, maka akan sulit bagi usaha ini untuk bersaing dan berkembang. Sehingga fokus masalah yang dihadapi adalah pembenahan masalah strategi manajemen dan pembukuan yang belum.

Berdasarkan analisis diatas, pelaku usaha pengrajin kopiah tradisional Lili Koleksi sangat membutuhkan pelatihan dan pembenahan mengenai manajemen bisnis dan pembukuan yang sesuai dengan UMKM untuk mendukung kegiatan usaha agar dapat berkembang dengan baik kedepannya. Pemberian pelatihan dan pembenahan kegiatan ini disesuaikan dengan golongan UMKN untuk menunjang tingkat penjualan, mendapatkan pangsa pasar dan membantu menciptakan informasi keuangan. Tujuan akhir dari kegiatan ini diharapkan mitra dapat mengembangkan usahanya, melakukan inovasi, melakukan promosi dengan baik, dan melakukan pencatatan keuangan yang akurat yang dapat menunjang berlangsungan usaha di masa yang akan datang.

Dokumentasi Situasi Pengrajin Kopiah Tradisional Lili Koleksi Kecamatan Lubuk Kilangan Kota Padang:
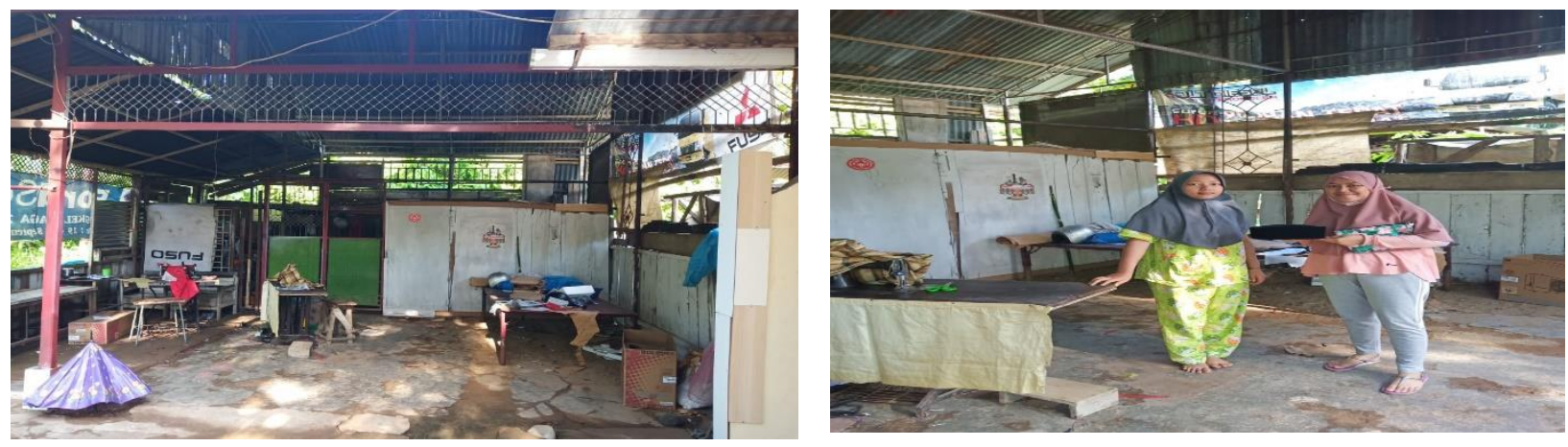

Gambar 1. Situasi Lili Koleksi

\section{Permasalahan Mitra}

Sejauh ini pengaplikasian manajemen bisnis dan pembukuan belum dilaksanakan dengan baik oleh mitra ini karena adanya keterbatasan sumber daya dalam hal mentransfer ilmu mengenai bagaimana manajemen bisnis yang baik dan bagaimana cara melakukan pembukuan untuk UMKM sesuai standar yang berlaku. Sementara dengan semakin berkembangnya era bisnis saat ini, dimana para pebisnis sudah menggunakan 
teknik pemasaran digital yang dapat meningkatkan perkembangan usaha, mitra ini masih jauh ketertinggalannya dalam mengelola usaha. Menanggapi permasalahan tersebut, tim penulis ingin memberikan pelatihan dan pembenahan mengenai manajemen bisnis dan pembukuan terkait keuangan. Manajemen bisnis yang baik tersebut harus mencakup bagaimana melakukan sebuah perencanaan, promosi, serta pengawasan yang dirasa sangat dibutuhkan pada mitra ini untuk mendukung usahanya. Dengan mengetahui manajemen bisnis yang tepat sasaran, usaha ini dapat memperluas pangsa pasarnya, mampu bersaing, dan berinovasi dengan baik. Selain itu tim penulis juga akan melakukan pelatihan terkait pembukuan. Dengan adanya pembukuan, usaha ini dapat melihat posisi keuangannya dan menjadikan informasi tersebut sebagai dasar dalam pengambilan keputusan ekonomis dimasa yang akan datangdemi memperkuat perekonomian.

Masalah yang menjadi prioritas utama untuk diatasi pada kegiatan ini adalah dengan:

1. Pelatihan

Pelatihan mengenai manajemen bisnis dan pembukuan yang sesuai bagi pengrajin kopiah tradisional. Pelatihan ini salah satu metode yang cocok diterapkan untuk mentransfer ilmu mengenai cara menyikapi usaha, mengatur strategi yang cocok untuk diterapkan pada usaha ini dan pembuatan pembukuan keuangan. Sehingga transfer ilmu ini bisa diaplikasikan langsung oleh pemilik usaha untuk membantu mengembangkan usahanya dan bertahan dimasa yang akan datang.

2. Pembenahan

Pembenahan pada kegiatan ini meliputi kegiatan perbaikan, peningkatan kualitas promosi, pemasaran serta menciptakan inovasi yang tergolong dalam manajemen bisnis dan dilakukan pembenahan mengenai cara melakukan pembukuan terkait data-data keuangan pada usaha ini. Selain dilakukan pembenahan, akan dilakukan juga evaluasi secara berkala terhadap pengaplikasian dari strategi pemsaran untuk melihat sejauh mana ilmu yang telah diberikan dapat memperbaiki dan mengembangkan usaha kopiah tradisional ini.

\section{Solusi yang Ditawarkan}

Solusi yang ditawarkan untuk menyelesaikan permasalahan yang dihadapi mitra adalah:

1. Memberikan pelatihan dan pembenahan

2. Memberikan monitoring

\section{Target dan Luaran}

1. Target pada kegiatan ini adalah memberikan manajemen bisnis dan pembukuan yang cocok diterapkan untuk UMKM.

2. Luaran yang dihasilkan adalah modul manajemen bisnis dan pembukuan yang tepat dan cocok untuk diterapkan oleh usaha UMKM ini. Disamping itu rencana capaian luaran yang ditargetkan dapat dilihat pada tabel dibawah ini :

Tabel 1. Rencana Target Capaian Luaran

\begin{tabular}{|l|l|c|}
\hline No & \multicolumn{1}{|c|}{ Jenis Luaran } & \multicolumn{1}{|l|}{ Indikator Capaian } \\
\hline \multicolumn{2}{|l|}{ Luaran Wajib } & Accepted/Summitted \\
\hline 1 & $\begin{array}{l}\text { Publikasi Ilmiah pada Jurnal ber ISSN/Prosiding Jurnal } \\
\text { Nasional }^{1)}\end{array}$ \\
\hline
\end{tabular}




\begin{tabular}{|c|c|c|}
\hline 2 & Publikasi pada media masa cetak/online/repocitory PT6) & Published \\
\hline 3 & $\begin{array}{l}\text { Peningkatan daya saing (peningkatan kualitas, kuantitas, } \\
\text { serta nilai tambah barang, jasa, diversifikasi produk, atau } \\
\text { sumber daya lainnya) }\end{array}$ & Penerapan \\
\hline 4 & $\begin{array}{l}\text { Peningkatan penerapan iptek di masyarakat (mekanisme, } \\
\text { IT, dan manajemen) }{ }^{4} \text { ) }\end{array}$ & Penerapan \\
\hline 5 & $\begin{array}{l}\text { Perbaikan tata nilai masyarakat (seni budaya, sosial, } \\
\text { politik, keamanan, ketentraman, pendidikan, kesehatan)2) }\end{array}$ & Sudah dilaksanakan \\
\hline \multicolumn{3}{|c|}{ Luaran Tambahan } \\
\hline 1 & Publikasi di jurnal internasional ${ }^{1)}$ & Tidak Ada \\
\hline 2 & $\begin{array}{l}\text { Jasa; rekayasa sosial, metode atau sistem, } \\
\text { produk/barang5) }\end{array}$ & Tidak Ada \\
\hline 3 & Inovasi baru TTG5) & Tidak Ada \\
\hline 4 & $\begin{array}{l}\text { Hak kekayaan intelektual (Paten, Paten sederhana, Hak } \\
\text { Cipta, Merek } \\
\text { dagang, Rahasia dagang, Desain Produk Industri, } \\
\text { Perlindungan Varietas } \\
\text { Tanaman, Perlindungan Desain Topografi Sirkuit } \\
\text { Terpadu) }{ }^{3)}\end{array}$ & Tidak Ada \\
\hline 5 & Buku ber ISBN6) & Tidak Ada \\
\hline 6 & Video & Published \\
\hline
\end{tabular}

\section{Metode Pelaksanaan}

Metode pelaksanaan dalam kegiatan Pengabdian Kepada Masyarakat ini akan dibagi menjadi tiga tahap, yaitu tahap awal, tahap pelaksanaan, dan tahap akhir. Pada tahap awal dilaksanakan observasi dan wawancara secara langsung dengan pemilik dan pekerja dari Lili Koleksi. Hal ini bertujuan untuk mengetahui gambaran mengenai kondisi dan permasalahan yang terjadi selama ini. Pada tahap kedua akan dilakukan tahap pelaksanaan berupa pelatihan dan pembenahan mengenai manajemen bisnis dan pembukuan pada mitra yang ditunjuk yaitu Lili Koleksi selaku pengrajin kopiah tradisional. Kegiatan pelatihan dan pembenahan ini bertujuan untuk meningkatkan dan mengembangkan serta memperbaiki system penjualan menggunakan konsep manajemen bisnis dan pembukuan yang tepat sasaran. Pada tahap terakhir, yaitu tahap monitoring. Pada tahap ini dilakukan metode coaching, dimana pemilik memperlihatkan progress dengan menceritakan hambatan dan kesulitan yang dihadapi dalam melakukan proses bisnis. Adapun sasaran dari kegiatan ini adalah:

1. Membantu mitra menjalankan usaha dengan manajemen bisnis yang tepat sasaran

2. Mampu bersaing dan memiliki pangsa pasar yang luas melalui penerapan manajemen bisnis yang terstruktur

3. Mampu meningkatkan omzet dan mempertahankan usaha kerajinan

4. Mampu melakukan pembukuan terkait keuangan untuk pengawasan dan pengambilan keputusan ekonomis. 
Prosedur Kerja

Pada pengabdian kepada masyarakat ini dilakukan prosedur kerja sebagai berikut:

Tabel 2. Prosedur Kerja

\begin{tabular}{|l|l|l|}
\hline \multicolumn{1}{|c|}{ Tahapan } & \multicolumn{1}{|c|}{ Metode } & \multicolumn{1}{c|}{ Keterangan } \\
\hline Tahap Awal & $\begin{array}{l}\text { 1. Observasi } \\
\text { 2. Wawancara }\end{array}$ & $\begin{array}{l}\text { Memperoleh gambaran } \\
\text { awal dan permasalahan } \\
\text { yang dihadapi mitra }\end{array}$ \\
\hline Tahap Pelaksanaan & $\begin{array}{l}\text { 1. Pelatihan } \\
\text { 2. Pembenahan }\end{array}$ & $\begin{array}{l}\text { Peserta memperoleh } \\
\text { transfer ilmu }\end{array}$ \\
\hline Tahap akhir & Monitoring mitra & $\begin{array}{l}\text { Diharapkan mitra dapat } \\
\text { mengaplikasikan ilmu } \\
\text { strategi pemasaran }\end{array}$ \\
\hline
\end{tabular}

\section{Partisipasi Mitra}

Mitra dalam hal ini adalah pemilik usaha dan pengelola usaha yaitu ibu Candra Wita dan Lili. Parsipasi mitra dalam kegiatan ini adalah:

1. Menyediakan tempat dan peralatan untuk kegiatan pelatihan dan pembenahan.

2. Memiliki keinginan dan motivasi untuk mengikuti kegiatan pelatihan dan pembenahan mengenai manajemen bisnis dan pembukuan demi keberlangsungan usaha dimasa yang akan datang.

\section{Evaluasi Program dan Keberlanjutan Program}

Evaluasi dilakukan secara langsung pada saat simulasi selama kegiatan berlangsung. Tujuan evaluasi ini adalah untuk perbaikan pelaksanaan berikutnya dan seandainya ada hambatan, maka akan didiskusikan dengan mitra untuk mencarikan solusi dan perbaikannya. Diharapkan ke depan akan terjalin kerjasama antara mitra dengan Politeknik Negeri Padang.

\section{Analisis Kebutuhan Mitra}

Kebutuhan mitra adalah sebagai berikut:

1. Membutuhkan pengetahuan dan pemahaman mengenai strategi manajemen yang cocok untuk UMKN dan ilmu mengenai pembukuan untuk mencatat hasil usaha.

2. Membutuhkan arahan yang jelas dalam hal pengembangan usaha dimasa yang akan datang. 
3. Membutuhkan bimbingan dalam mengikuti perubahan digital untuk mampu bertahan dan mengembangkan usaha menggunakan media elektronik.

\section{Hasil}

Adapun hasil yang telah diperoleh dari kegiatan ini adalah:

1. Peningkatan ilmu mengenai penerapan strategi manajemen bisnis dalam hal memgembangkan usaha.

2. Peningkatan ilmu dan keterampilan dalam hal melakukan pembukuan atas hasil usaha.

3. Peningkatan keterampilan menggunakan media elektronik untuk mendukung usaha.

\section{Ucapan Terima Kasih}

1. Politeknik Negeri Padang yang telah memberikan kesempatan dan bantuan dalam menyelesaikan kegiatan ini.

2. Bapak Surfa Yondri, ST.,S.ST.,M.Kom selaku Direktur Politeknik Negeri Padang.

3. Bapak Dr. Yuhefizar, S.Kom., M.Kom selaku Kepala P3M Politeknik Negeri Padang.

4. Ibu Dr. Amy Fontanella, SE.,M.Si.,Ak selaku Ketua Jurusan Akuntansi Politeknik Negeri Padang.

5. Rekan-rekan Jurusan Akuntansi Politeknik Negeri Padang.

\section{Referensi}

Anonim. (2019, 21 Des). “Kontribusi Ekonomis Kreatif terhadap PDB Indonesia”. Diperoleh tanggal 2 Februari 2020 dari: (http://kompas.id/baca/adv_post/kontribusiekonomi-kreatif -terhadap-pdb-indonesia//)).

Kotler, Philip dan Kevin Lane Keller. 2012. Managemen Pemasaran Jilid 1 dan 2. Erlangga. Jakarta 